\title{
Alkali-activated materials: the role of molecular-scale research and lessons from the energy transition to combat climate change
}

\author{
Claire E. White ${ }^{a, b \circ *}$ \\ ${ }^{a}$ Department of Civil and Environmental Engineering, Princeton University, Princeton, NJ, 08544, USA \\ ${ }^{\mathrm{b}}$ Andlinger Center for Energy and the Environment, Princeton University, Princeton, NJ, 08544, USA \\ - The author was invited for submission of this letter as an awardee of the Gustavo Colonnetti Medal granted by RILEM in 2019.
}

Received: 24 September 2019 / Accepted: 21 January 2020 / Published online: 28 January 2020

(c) The Author(s) 2020. This article is published with open access and licensed under a Creative Commons Attribution 4.0 International License.

\begin{abstract}
Alternative (i.e., non-Portland) cements, such as alkali-activated materials, have gained significant interest from the scientific community due to their proven $\mathrm{CO}_{2}$ savings compared with Portland cement together with known short-term performance properties. However, the concrete industry remains dominated by Portland cement-based concrete. This Letter explores the technical and non-technical hurdles preventing implementation of an alternative cement, such as alkali-activated materials, in the concrete industry and discusses how these hurdles can be overcome. Specifically, it is shown that certain technical hurdles, such as a lack of understanding how certain additives affect setting of alkali-activated materials (and Portland cement) and the absence of long-term in-field performance data of these sustainable cements, can be mitigated via the use of key molecular- and nano-scale experimental techniques to elucidate dominant material characteristics, including those that control long-term performance. In the second part of this Letter the concrete industry is compared and contrasted with the electricity generation industry, and specifically the transition from one dominant technology (i.e., coal) to a diverse array of energy sources including renewables. It is concluded that financial incentives and public advocacy (akin to advocacy for renewables in the energy sector) would significantly enhance uptake of alternative cements in the concrete industry.
\end{abstract}

Keywords: Sustainability; alternative cements; durability; alkali-activated concrete; materials science

\section{Introduction}

The quest for alternative (i.e., non-Portland) cements that are more sustainable than Portland cement is motivated by the large $\mathrm{CO}_{2}$ emissions associated with Portland cement manufacturing around the world. Currently, the cement industry is responsible for $5-8 \%$ of anthropogenic $\mathrm{CO}_{2}$ emissions ( $2.2 \mathrm{Gt} /$ year in 2014) [1], and cement's share of all $\mathrm{CO}_{2}$ emissions is forecast to increase in the future. Historically, driving forces to increase longevity of cement-based materials have led to the blending of the cement powder with industrial byproducts (such as blast furnace slag from cast iron production and coal-derived fly ash) [2], that augment the fundamental structure of the main binder gel, calciumsilicate-hydrate (C-S-H). More recently, the utilization of these industrial byproducts and natural minerals has gained significant attention from government and industry due to the enhanced sustainability aspects via the use of less Portland cement (and lower associated $\mathrm{CO}_{2}$ emissions) in a given amount of concrete [2].

It is becoming increasingly apparent that emerging disruptive concrete technologies (i.e., alternative cements) are gaining traction, especially in the research community, since they have the capability to significantly reduce $\mathrm{CO}_{2}$ emissions in the concrete industry. However, their current usage in this industry is minimal. There are a number of reasons why this usage is negligible, one of which pertains to the lack of extensive in-field data proving long-term performance for one hundred years or more. Other reasons tend to revolve around non-technical aspects, such as resource availability, supply chain logistics, cost, compliance with construction codes, and a lack of familiarity with alternative cements in the industry. In this Letter, recent research on alkali-activated materials (AAMs), one type of alternative cement, is presented, where carefully selected nano- and molecularscale experimental techniques are utilized (i) to elucidate the mechanisms by which certain additives augment setting of AAMs without compromising on long-term performance, and (ii) to accurately characterize and compare paste attributes that contribute to long-term performance (i.e., durability). These examples show that it is possible to purposely manipulate the performance of an alternative cement, such as AAMs, to enhance in-field behavior and therefore

* Corresponding author: Claire E. White, +1 609258 6263, Fax: +1 609258 2799, Email: whitece@princeton.edu 
accelerate implementation of the material in the concrete industry.

The non-technical aspects limiting uptake of alternative cements are often highlighted as reasons why Portland cement will remain the dominant technology moving forward. This argument is reminiscent of coal usage for electricity generation, where approximately one hundred years ago coal dominated the energy sector. However, since the early 1900s there have been significant advances made in the energy sector via implementation of alternatives such as nuclear, solar and wind generation. This energy transition is discussed in this Letter together with the perceived hurdles facing the concrete industry thought to be preventing a similar transition via the implementation of a range of alternative cements. By comparing and contrasting the two industries (i.e., energy and concrete), this Letter seeks to encourage readers to consider what has helped cultivate sustainability successes in the energy industry, and whether such approaches could also help enhance the uptake of sustainable alternative cements in the concrete industry.

\section{Early-age behavior of alkali-activated materials}

The early-age behavior of AAMs, including precursor dissolution and gel precipitation, is strongly correlated with long-term performance. For example, adequate dissolution of the precursors will allow for ample gel formation, and therefore good mechanical strength development. Approaches to quantify the extent of reaction have been developed, such as those focused on quantification of unreacted precursor (via scanning electron microscopy or Xray diffraction). A comprehensive review by Provis et al. discussed the various techniques available for quantification, and outstanding questions that should be addressed by future research [3]. Another early-age behavior known to influence long-term performance is pore structure development. Concrete is a porous material, and the pore size controlling transport properties will dictate resistance to certain forms of degradation (often related to steel corrosion), where larger pores making up the percolated pore network lead to faster degradation rates [4].

There is a push to lower the alkalinity of the activators used for synthesis of AAMs to improve health and safety concerns associated with the use of this class of material in industry. Historically, it has been found that high $\mathrm{pH}$ activators are required to obtain sufficient dissolution of low-Ca AAM precursors, such as metakaolin and class $\mathrm{F}$ fly ash, and therefore hydroxide and silicate-based activators have been prevalent (such as sodium hydroxide and sodium silicate liquids) with $\mathrm{pH}$ levels of $\sim 13-14$ and higher. Hence, additives that enhance precursor dissolution, and subsequent gel precipitation are sorely needed, especially for low-Ca AAM systems. Although heat can be used as a method to enhance early-age strength development, there are energy costs associated with this form of treatment and such an approach will restrict low-Ca AAMs to the precast industry. Moreover, the ability to slow down setting and improve workability is needed for certain AAM systems [5,6], since conventional organic additives used in Portland cement concrete have been found to be ineffective.

In this Letter, three examples are presented where molecular/nano-scale research has provided key insight on the behavior of AAMs that contributes to long-term performance. This small collection of research examples exemplifies the type of approaches necessary for predicting long-term performance in addition to the standard durability testing approaches being developed by the wider research community.

\subsection{Manipulating the rate of gel formation: effect of nano-ZnO}

The ability to manipulate setting time of Portland cement concrete is extremely important for the construction industry, and a range of additives exist where usage depends on the exact needs at the construction site. However, such additives are often found to be ineffective when used in AAMs (especially the organic additives), and therefore new additives need to be developed. One additive that is known to be effective in Portland cement is zinc oxide ( $\mathrm{nnO})$. This additive delays setting of Portland cement, however, the underlying mechanism responsible for this behavior has been repeatedly debated in the literature for decades $[7,8]$. Moreover, the impact of $\mathrm{ZnO}$ on the formation of AAMs has remained essentially unexplored, which raises the question if $\mathrm{ZnO}$ has a similar delaying effect in AAMs. Our recent investigation on the impact of nano-ZnO on the formation of AAMs using isothermal calorimetry (ICC) and in situ X-ray pair distribution function (PDF) analysis revealed that calcium plays a crucial role in the ability of $\mathrm{ZnO}$ to delay gel formation [9]. ICC data from the study are given in Figure 1, where it is clear that the nano-ZnO dose has a substantial impact on the cumulative heat curve of alkali-activated blast furnace slag (AAS), and specifically the time at which the cumulative heat significantly increases (occurs at $\sim 10 \mathrm{hrs}$ for neat AAS and $\sim 35 \mathrm{hrs}$ for AAS containing $1.0 \mathrm{wt}$. \% nano-ZnO, relative to amount of slag). By $90 \mathrm{hrs}$ all four ICC curves approach a common cumulative heat value, indicating that this additive does not impact the overall extent of sodium-containing calcium-alumino-silicatehydrate (C-(N)-A-S-H) gel precipitation in AAS. On the other hand, ICC data on alkali-activated metakaolin (AAMK) with and without nano-ZnO (see ref. 9) show that this additive has no impact on the reaction kinetics of this $A A M$, indicating that calcium is integral to the efficacy of nano-ZnO in AAMs (and Portland cement).

To elucidate the mechanism by which nano-ZnO impacts the formation of $\mathrm{C}-(\mathrm{N})-\mathrm{A}-\mathrm{S}-\mathrm{H}$ gel in $\mathrm{AAS}$, an experimental technique capable of tracking phase evolution (both amorphous and crystalline phases) within a sample was needed. PDF analysis is an ideal technique for characterizing disordered materials, since a PDF dataset is a histogram of all atom-atom correlations within a sample. Furthermore, the high flux associated with synchrotron-based X-rays (or spallation neutrons) enables for time-resolved studies to be performed, including those focused on cementitious materials. The formation of AAS is depicted in Figure 2, where in situ X-ray PDFs show that the local atomic structure of the sample is changing as slag dissolves and C-(N)-A-S-H gel (and 
a hydrotalcite-like secondary phase) precipitates. In situ PDF datasets were also obtained for AAS with $0.1,0.5$ and 1.0 wt. $\%$ nano-ZnO. Further details on sample synthesis and characterization methods can be found in [9].

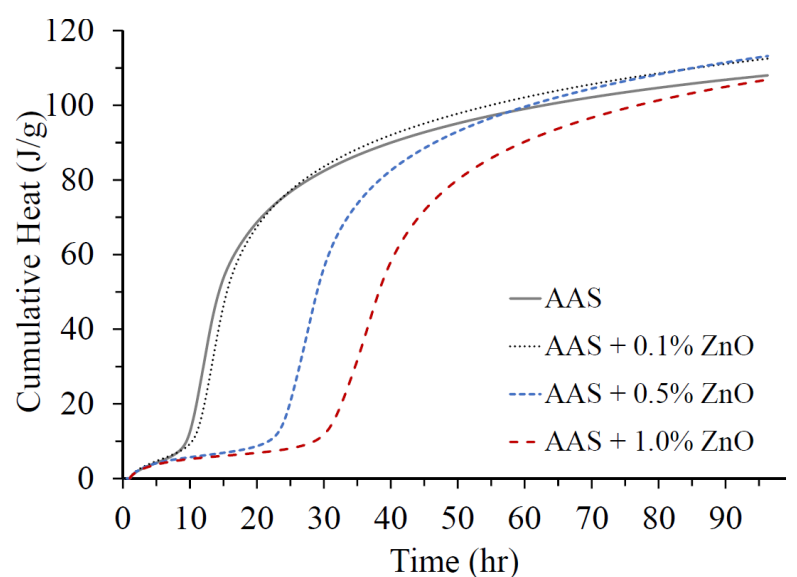

Figure 1. Isothermal conduction calorimetry cumulative heat curves of neat alkali-activated slag (AAS) synthesized using a sodium silicate activator ( 4 wt. $\% \mathrm{Na}_{2} \mathrm{O}$ relative to slag, $\mathrm{SiO}_{2} / \mathrm{Na}_{2} \mathrm{O}$ molar ratio of 1.0 for activator and water/slag wt. ratio of 0.44 ), and AAS with $0.1 \%$, $0.5 \%$ and $1.0 \%$ nano-ZnO (by wt. relative to amount of slag). The nano-ZnO was added to the activator immediately prior to sample synthesis.

There are numerous approaches that can be used to analyze PDF data, depending on the scientific question(s) being addressed [10]. In our study [9], the formation of intermediate phases was of interest since previous investigations reported several hypotheses for why $\mathrm{ZnO}$ delays the setting of Portland cement, specifically the formation of $\mathrm{Zn}(\mathrm{OH})_{2}$ [7] or calcium zincate (denoted as $\mathrm{CZ}$, $\left.\mathrm{Ca}\left(\mathrm{Zn}(\mathrm{OH})_{3}\right)_{2} \cdot 2 \mathrm{H}_{2} \mathrm{O}\right)$ [8]. One approach for data analysis that is particularly useful for identifying and analyzing intermediate phases is by taking difference curves of the PDF data, as has been carried out in Figure 3. In ref. 9 these difference curves were compared with several phases hypothesized to potentially form when $\mathrm{ZnO}$ is added to Portland cement paste, and, as shown in Figure 3, CZ was found to provide the best agreement, especially by the appearance and subsequent disappearance of the intensity at $3.42 \AA$, which is assigned to the $\mathrm{Zn}-\mathrm{Zn}$ correlation in this phase. Moreover, analysis of these difference curves for AAS with different amounts of nano-ZnO as a function of time, and specifically the PDF intensity at $3.42 \AA$ (Figure 4 ) revealed that the $C Z$ is present during the initial stages of the alkali activation reaction. However, the disappearance of $\mathrm{CZ}$ coincides with the significant increase in cumulative heat seen in Figure 1, indicating that $\mathrm{C}-(\mathrm{N})-\mathrm{A}-\mathrm{S}-\mathrm{H}$ gel precipitates in conjunction with the disappearance of $\mathrm{CZ}$.

The mechanism by which nano-ZnO delays $\mathrm{C}-(\mathrm{N})-\mathrm{A}-\mathrm{S}-\mathrm{H}$ gel precipitation (and setting) of AAS was determined from the above data (Figures 2, 3 and 4) together with analysis of reciprocal space $X$-ray data, including the behavior of nano$\mathrm{ZnO}$ and $\mathrm{C}-(\mathrm{N})-\mathrm{A}-\mathrm{S}-\mathrm{H}$ gel. From these data it was determined that nano-ZnO dissolves during the initial stages of the alkali activation of slag, leading to formation of $\mathrm{CZ}$ via the reaction of aqueous zinc hydroxide species and calcium from slag dissolution. Provided that $\mathrm{ZnO}$ is present in the system (i.e., unreacted $\mathrm{ZnO}$ ), calcium will quickly be consumed by zinc to form $C Z$, preventing the aqueous solution from reaching saturation with respect to $\mathrm{C}-(\mathrm{N})-\mathrm{A}-\mathrm{S}-\mathrm{H}$ gel. Once all $\mathrm{ZnO}$ has been consumed, and converted into $\mathrm{CZ}$, additional slag dissolution leads to the formation of $\mathrm{C}-(\mathrm{N})-\mathrm{A}-\mathrm{S}-\mathrm{H}$ gel, which coincides with the significant increase in cumulative heat observed in Figure 1 [9]. CZ is found to be a metastable phase, and therefore is not present in the samples at later age. Instead, it is postulated that zinc is likely incorporated into C(N)-A-S-H gel [11].

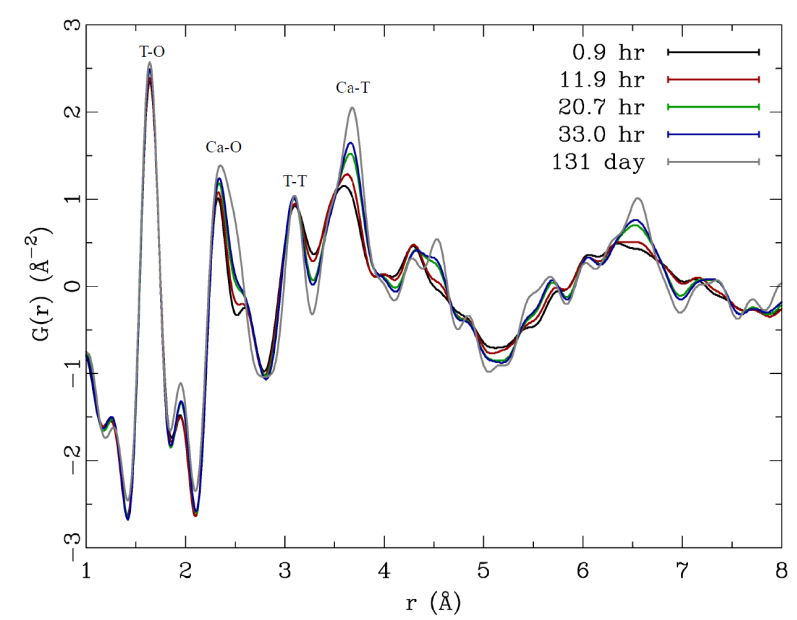

Figure 2. In situ X-ray pair distribution functions of neat alkaliactivated slag (AAS) during the formation reaction up to 131 days. Specific atom-atom correlations are labeled including the T-O bond length (were $T$ denotes silicon and aluminum in 4-fold coordination), $\mathrm{Ca}-\mathrm{O}$ bond length, and the T-T and Ca-T correlations. Data were collected on beamline 11-ID-B at the Advanced Photon Source, Argonne National Laboratory. The sample was measured in situ up to $33 \mathrm{hrs}$, and was re-measured at 131 days on the same beamline. Ref. 9 provides a comprehensive overview of sample synthesis and measurement parameters for this study.

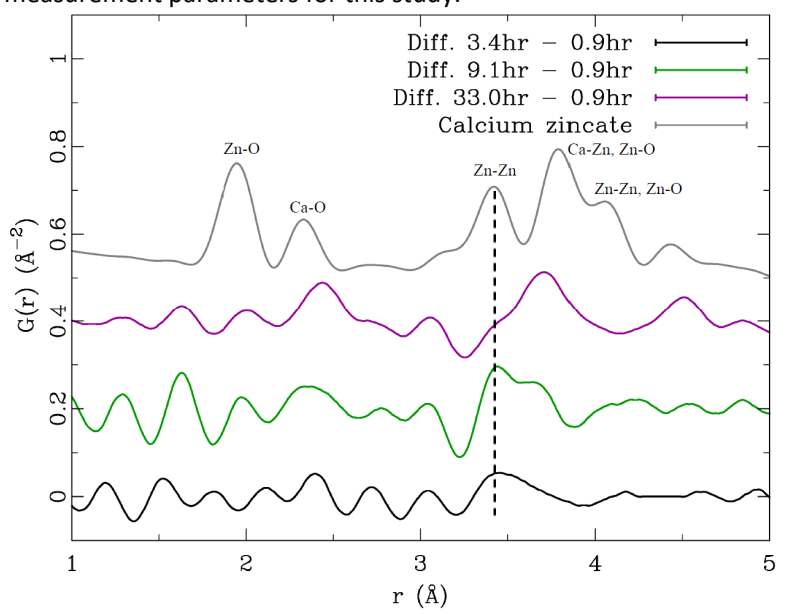

Figure 3. In situ X-ray pair distribution function difference curves of alkali-activated slag (AAS) with $0.5 \mathrm{wt}$. \% nano-ZnO (relative to amount of slag) as a function of reaction time. Each difference curve was obtained by subtracting the initial curve $(0.9 \mathrm{hr})$ from the curve at the designed time (e.g., "33.0hr - 0.9hr" denotes the difference curve obtained by subtracting the $0.9 \mathrm{hr}$ curve from the $33.0 \mathrm{hr}$ pair distribution function). The simulated $\mathrm{X}$-ray pair distribution function of calcium zincate (CZ) is also provided, where the $\mathrm{Zn}-\mathrm{Zn}$ correlation at $3.42 \AA$ is labeled and compared with the intensities of the difference curves. 


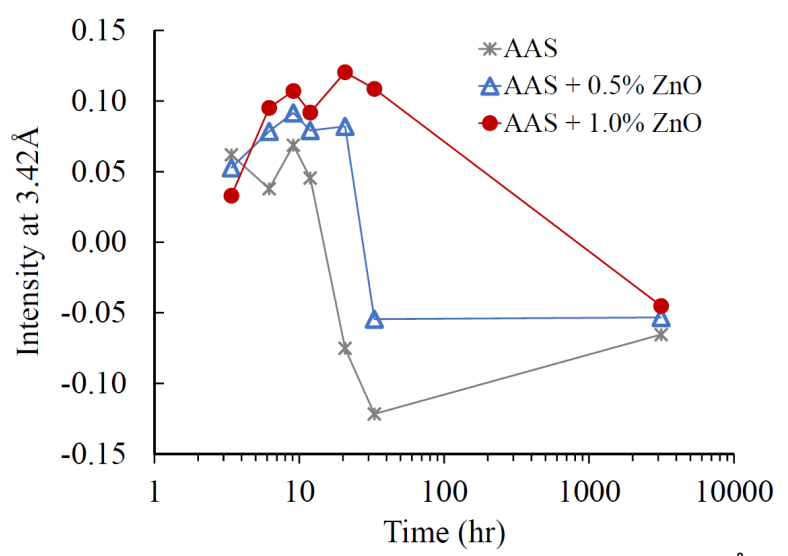

Figure 4. Intensity of the difference curves (see Figure 3 ) at $3.42 \AA$ as a function of the reaction time for neat alkali-activated slag (AAS), and AAS with $0.5 \%$ and $1.0 \%$ nano-ZnO. The difference curves were obtained by subtracting the initial curve $(0.9 \mathrm{hr})$ from the curve at the designed times.

It is clear from the above example that the impact of additives on the molecular-scale mechanisms responsible for formation of AAS can be elucidated. This fundamental knowledge, including determination of the long-term fate of the additives, is important for predicting long-term performance. For example, if the additive was seen to lower the total amount of $\mathrm{C}-(\mathrm{N})-\mathrm{A}-\mathrm{S}-\mathrm{H}$ gel that formed, then this would impact strength development, and potentially disrupt the formation of a low permeability paste. Furthermore, if $\mathrm{Zn}$ was found to reside long-term in the pore solution as opposed to the $\mathrm{C}-(\mathrm{N})-\mathrm{A}-\mathrm{S}-\mathrm{H}$ gel, then potential leaching of this heavy metal would become a significant concern. Hence, by using key molecular-scale research approaches, such as PDF analysis combined with conventional laboratory techniques, a more complete picture of the paste behavior can be determined, enhancing our ability to be able to predict longterm performance of such alternative cements.

\subsection{Pore structure evolution}

The durability of concrete is intimately linked with its pore structure, since it is well known that the pore network controls various degradation mechanisms, including the ingress of chemicals that can cause steel corrosion (such as carbon dioxide and chloride) [12], resistance to freeze-thaw (via the incorporation of air voids) and wet-dry cycling. Concrete consists of pores ranging from a few nanometers up to millimeters, where the percolated pore network tends to reside in the 10s-100s $\mathrm{nm}$ [13], and air voids are $\sim 100 \mu \mathrm{m}$. There are a number of experimental techniques capable of accessing various details on the pore structure of a cementbased material (e.g., small-angle scattering, ${ }^{1} \mathrm{H}$ nuclear magnetic resonance, $\mathrm{X}$-ray nano- and micro-tomography, nitrogen sorption, mercury intrusion porosimetry, and transmission electron microscopy), some of which require sample pretreatment which potentially alters the pore structure prior to measurement (e.g., nitrogen sorption, mercury intrusion porosimetry, and standard scanning and transmission electron microscopy). However, recent investigations have shown that techniques such as nitrogen sorption and mercury intrusion porosimetry can provide important quantitative data on the pore structure of a cement-based material, particularly when a mild form of drying is used in conjunction with an alcohol exchange $[14,15]$.

It has been previously shown that the percolated pore network in Portland cement paste (with w/c ratio of 0.5 ) is made up of pore entries-exits that are $\sim 3 \mathrm{~nm}$ in size, which was also found to be the case for silicate-activated slag in our previous study [4], as measured using nitrogen desorption analysis (for samples synthesized using $7 \mathrm{wt} \% \mathrm{Na}_{2} \mathrm{O}$ relative to slag, $\mathrm{SiO}_{2} / \mathrm{Na}_{2} \mathrm{O}$ molar ratio of 1 for the activator, and water/slag wt. ratio of 0.5 ). Nitrogen adsorption leads to slightly different results, since this approach probes the pore interiors, which tend to be larger than the corresponding pore entries-exits. For silicate-activated slag, nitrogen adsorption has revealed that the pore interiors are initially $\sim 10 \mathrm{~nm}$ in diameter (up to $\sim 20$ days), after which their amount decreases across all pore sizes accessible using nitrogen sorption indicating a depercolation of the pore network [4]. In contrast to the relatively small pore sizes making up the pore network in silicate-activated slag, hydroxide-activated slag consists of pores of $\sim 30 \mathrm{~nm}$ in diameter (at $\sim 20$ days, for sodium hydroxide activator with 7 wt. $\% \mathrm{Na}_{2} \mathrm{O}$ relative to slag), as measured using mercury intrusion porosimetry [4]. Hence, it is clear that the presence of free silica in the activator has a significant impact on the resultant pore structure of AAS paste.

A similar analysis of AAMK is performed here for sodium hydroxide-, hydroxide/silicate- and silicate-based activators. MetaMax from BASF served as the metakaolin source, and activators were synthesized using 28 wt. $\% \mathrm{Na}_{2} \mathrm{O}$ with $\mathrm{SiO}_{2} / \mathrm{Na}_{2} \mathrm{O}$ molar ratios of 0,1 , and 2 (denoted as hydroxide-, hydroxide/silicate- and silicate-, respectively). Samples were produced using a water/metakaolin wt. ratio of 0.9. Prior to analysis using nitrogen adsorption or mercury intrusion porosimetry, samples were crushed into $1-2 \mathrm{~mm}$ pieces and soaked for $24 \mathrm{hrs}$ in isopropyl alcohol ( 1 g sample for $100 \mathrm{~mL}$ alcohol), then removed from the alcohol and dried at ambient temperature under vacuum for $24 \mathrm{hrs}$. Nitrogen sorption measurements were performed on a Micromeritics 3Flex instrument, Norcross GA, with initial degassing carried out on a Micromeritics Smart VacPrep067. Mercury intrusion porosimetry was performed using a Micromeritics AutoPore $\mathrm{V}$ instrument.

Nitrogen adsorption data for AAMK are given in Figure 5 for samples at 7 and 150 days after mixing. If this technique were to be used in isolation to understand the pore structure of AAMK, and specifically early-age hydroxide-activated metakaolin, an incomplete and erroneous conclusion would be drawn. Specifically, the nitrogen adsorption data indicate that hydroxide-activated metakaolin has very low porosity (cumulative pore volume) at 7 days, and at 150 days this sample possesses a similar porosity to silicate-activated metakaolin. However, from mercury intrusion porosimetry (Figure 6) it is clear that hydroxide-activated metakaolin is very porous at early age ( 7 days), with $\sim 45 \%$ higher porosity (cumulative pore volume) compared with hydroxide/silicateactivated metakaolin. Furthermore, the breakthrough pore 
diameter (i.e., the pore size controlling permeability and ingress of chemicals) at 6 days is $\sim 200 \mathrm{~nm}$, compared with $\sim 20$ $\mathrm{nm}$ for hydroxide/silicate-activated metakaolin. Hence, the pore network of hydroxide-activated metakaolin is outside the measurement range of nitrogen adsorption $(\sim 50 \mathrm{~nm}$ is the upper limit for this technique), warranting the use of mercury intrusion porosimetry (or another technique sensitive to pores $>50 \mathrm{~nm}$ in size) to obtain accurate information. Even at 900 days the pore network of hydroxide-activated metakaolin consists of pores with an average diameter of $\sim 100 \mathrm{~nm}$ in size (Figure 6).

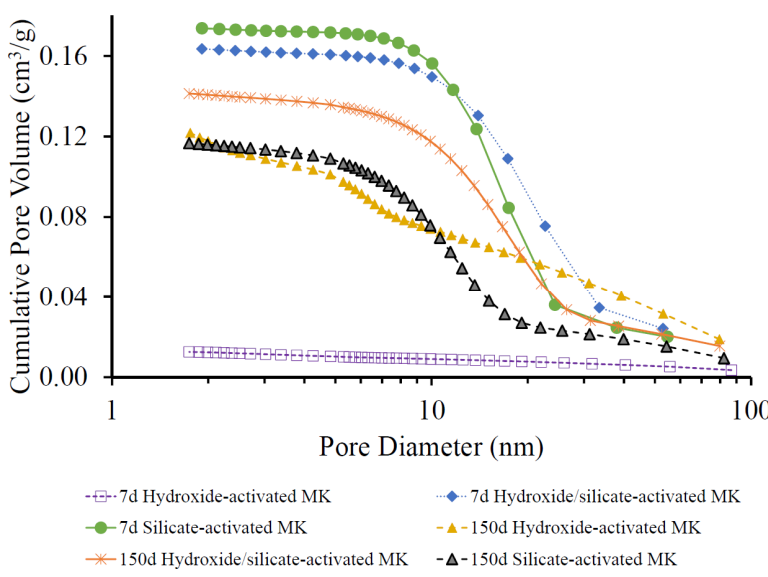

Figure 5. Nitrogen adsorption cumulative pore volume curves as a function of average pore diameter for hydroxide-, hydroxide/silicate-, and silicate-activated metakaolin (MK) at 7 and 150 days.

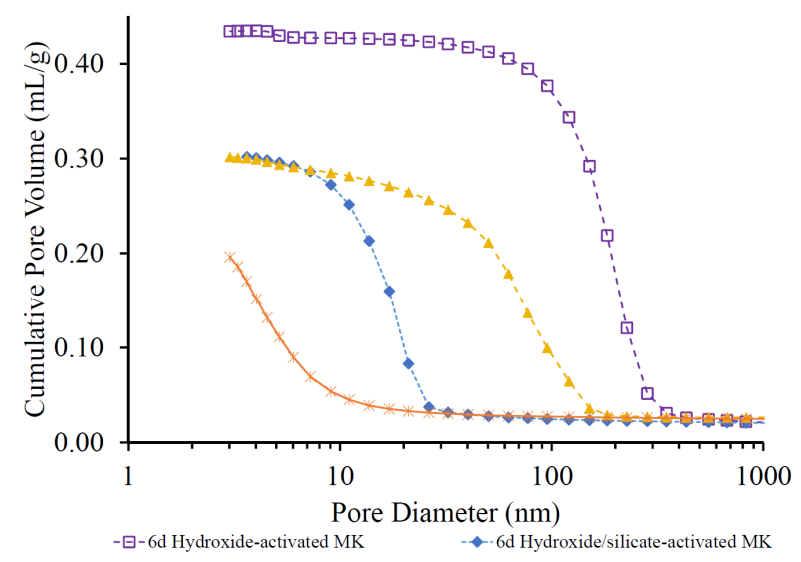

$\begin{array}{ll}-\bullet-6 \mathrm{~d} \text { Hydroxide-activated MK } & -6 \mathrm{~d} \text { Hydroxide/silicate-activated MK } \\ -\$ \text {-900d Hydroxide-activated MK } & * 900 \mathrm{~d} \text { Hydroxide/silicate-activated MK }\end{array}$ Figure 6. Mercury intrusion porosimetry cumulative pore volume curves as a function of average pore diameter for hydroxide- and hydroxide/silicate-activated metakaolin (MK) at 6 and 900 days.

As evident from both the nitrogen adsorption and mercury intrusion porosimetry data (Figures 5 and 6), hydroxide/silicate-activated metakaolin contains pores of $\sim 20 \mathrm{~nm}$ in diameter at $\sim 1$ week, which decrease slightly in size to $\sim 15 \mathrm{~nm}$ by 150 days (Figure 5) and smaller than $8 \mathrm{~nm}$ by 900 days (Figure 6, mercury intrusion porosimetry data accurate down to $7 \mathrm{~nm}$, below which crushing of sample can occur due to the extremely high pressures used for mercury intrusion). Hence, nitrogen adsorption analysis is able to fully capture the pore size distribution of hydroxide/silicateactivated metakaolin. This is also the case for silicateactivated metakaolin, which is seen to possess pores of $\sim 15$ $\mathrm{nm}$ in diameter at 7 days that shrink to $\sim 10 \mathrm{~nm}$ by 150 days (Figure 5).

Comparison of AAMK with AAS reveals that AAMK has pores that are approximately $2-5$ times larger than those in AAS (whilst keeping activator $\mathrm{SiO}_{2} / \mathrm{Na}_{2} \mathrm{O}$ molar ratio constant). This is likely partially attributed to the higher water demand of metakaolin synthesized using rotary kilns (in contrast to the lower water demand of metakaolin derived from flash calcination) together with the ability of the gels to actively incorporate water molecules (C-(N)-A-S-H gel contains interlayer water whereas sodium-alumino-silicate-hydrate (N-A-S-(H)) gel does not). In the future, it would be ideal to be able to determine the multiscale pore structure of a cementbased material from simulations without the need for timeconsuming experiments. Efforts are underway to develop such simulation techniques [16-18], however, the challenge remains of how to effectively simulate a multiscale pore structure that spans from a couple of nanometers up to the micron length scale.

From the results obtained in this section, it is clear that silicate-activated metakaolin will be more durable from a permeability standpoint compared with hydroxide-activated metakaolin due to the smaller breakthrough diameter of the pore structure $(\sim 15 \mathrm{~nm}$ for silicate-activated metakaolin at 7 days that decreases to $\sim 10 \mathrm{~nm}$ by 150 days). This is especially the case if steel reinforcement were to be used, since it is the pore solution $\mathrm{pH}$ that essentially controls steel corrosion, unless chlorides are present in which case the steel would be attacked even at high $\mathrm{pH}$ values. A breakthrough diameter of $10 \mathrm{~nm}$ is similar to the results obtained by Villadsen for Portland paste ( $\mathrm{w} / \mathrm{c}$ ratio of 0.4 ) at $\sim 80$ days using MIP (pores ranging from $20 \mathrm{~nm}$ down to the measurement limit of MIP, see Figure 4.3.2A in ref. 19). It is not just the pore size that controls permeability, but also the total porosity and tortuosity of the percolated pore structure. At the moment, rotary kiln-derived metakaolin has a relatively high water demand (water/metakaolin wt. ratio of 0.9), leading to a highly porous paste. However, flash calcined kaolin results in metakaolin with a reduced water demand [20], which will likely lead to AAMKs with porosities and pore structures comparable to Portland cement paste (research still to be conducted). Hence, certain metakaolin-containing AAMs may become industrially-feasible in the future, especially in light of the abundant availability of kaolin clays around the world together with ongoing research focused on lowering the alkalinity of the activators without compromising on strength development and durability.

\subsection{Nanoscale ordering of real and synthetic C- (N)-A-S-H gels}

As mentioned previously, the pore structure and associated permeability of cement paste is known to control certain durability aspects of concrete, particular those associated with corrosion of the steel reinforcement. In addition to these paste attributes, durability will also be influenced by the stability of the phases in cement paste, since chemical degradation such as carbonation and sulfate attack can significantly alter the pore solution composition including $\mathrm{pH}$ 
(for example, $\mathrm{CO}_{2}$ uptake lowers the pore solution $\mathrm{pH}$ ). Hence, the stability of phases in cement paste, and particularly those that provide strength to the composite material, will dictate the ability of the paste to resist chemically-induced degradation. However, to date the stabilities of C-S-H and C-A-S-H gels in Portland cement-based pastes, and $\mathrm{C}-(\mathrm{N})-\mathrm{A}-\mathrm{S}-\mathrm{H}$ and $\mathrm{N}-\mathrm{A}-\mathrm{S}-(\mathrm{H})$ gels in $\mathrm{AAM}$ s have been determined by synthesizing and analyzing phase pure gels in the laboratory. Although standard characterization techniques such as X-ray diffraction and thermogravimetry analysis have shown these real and synthetic phases to be similar, detailed analysis of the thermodynamics of the real gels has yet to be carried out. Here, information on the nanoscale ordering of real and synthetic $\mathrm{C}-(\mathrm{N})-\mathrm{A}-\mathrm{S}-\mathrm{H}$ gels is presented and discussed in the context of thermodynamic stability.

As mentioned in Section 2.1, PDF analysis is a useful characterization technique for cement-based materials since it can be used to elucidate the local atomic structure of disordered materials. Due to the heterogeneous nature of Portland cement paste, and specifically the presence of multiple reactant phases together with $\mathrm{C}-\mathrm{S}-\mathrm{H}$ gel, portlandite, ettringite and additional secondary products, it is extremely difficult to study the behavior of $\mathrm{C}-\mathrm{S}-\mathrm{H}$ gel in isolation. Therefore, various routes for synthesis of phase-pure C-S-H gel have been developed, allowing for the gel to be studied in detail, including determination of thermodynamic properties for use in geochemical models [21]. Synthetic C-(N)-A-S-H and $\mathrm{N}-\mathrm{A}-\mathrm{S}-(\mathrm{H})$ gels have also been studied in the past $[22,23]$, and subsequent thermodynamic modeling of phase assemblage in AAMs has been carried out and compared with experimental results. Analysis of these synthetic C-S-H, C-(N)A-S-H and N-A-S- $(\mathrm{H})$ gels for the purpose of better understanding Portland and alternative cements is based on the premise that the synthetic gels are representative of those found in the real systems.

We recently used synchrotron-based X-ray PDF analysis to study the extent of nanoscale ordering of real and synthetic gels in AAS [24]. The synthetic gels were synthesized by mixing $\mathrm{Ca}(\mathrm{OH})_{2}$, fumed silica and $\mathrm{NaAlO}_{2}$ in $1 \mathrm{M} \mathrm{NaOH}$ for 1 month. Chemical compositions of the synthetic gels are outlined in the caption of Figure 7. No unreacted $\mathrm{Ca}(\mathrm{OH})_{2}$ or fumed silica was present in these samples. The real gels were obtained by subtracting the PDF of unreacted blast furnace slag from the PDFs of the AAS samples. Details of this subtraction procedure are outlined in detail in [24].

Data from this recent investigation are given in Figure 7, where X-ray PDF analysis reveals that there are significant differences between the two gel types. Specifically, the synthetic C-(N)-A-S-H gels (shown in pastel colors) are significantly more ordered out to $6 \mathrm{~nm}$, meaning that they are distinctly nanocrystalline. Note that $8 \mathrm{~nm}$ is the approximate resolution limit of the 11-ID-B beamline setup used for the measurements so microcrystalline samples would possess atom-atom correlation out to $\sim 8 \mathrm{~nm}$. On the other hand, real C-(N)-A-S-H gels (shown in bold colors) possess a lower extent of nanoscale ordering, meaning that they are more disordered at the nanoscale than their synthetic counterparts. Although not shown here, the local atomic structure of the real and synthetic gels are comparable for similar $\mathrm{Ca} / \mathrm{Si}$ ratios [24], and therefore the differences seen in Figure 7 are a manifestation of the intrinsic dissimilarities in nanoscale ordering.

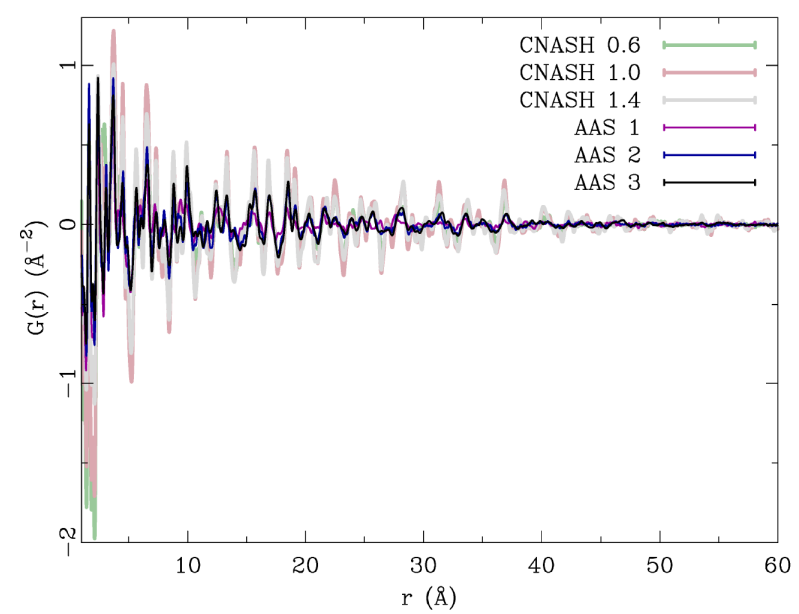

Figure 7. Synchrotron-derived $\mathrm{X}$-ray pair distribution functions of real and synthetic sodium-containing calcium-alumino-silicate-hydrate (C(N)-A-S-H) gels showing the extent of ordering in each sample. Three real C-(N)-A-S-H gels (denoted as AAS 1, AAS 2 and AAS 3) were obtained via subtraction of slag contributions (see ref. 24 for details), while the synthetic gels (CNASH 0.6, CNASH 1.0 and CNASH 1.4) were obtained via the reaction of $\mathrm{Ca}(\mathrm{OH})_{2}$, fumed silica and $\mathrm{NaAlO}_{2}$ in $1 \mathrm{M}$ $\mathrm{NaOH}$ where the $\mathrm{Al} / \mathrm{Si}$ ratio was 0.1 and the $\mathrm{Ca} / \mathrm{Si}$ ratio used for synthesis is denoted by the value in the sample name (i.e., a $\mathrm{Ca} / \mathrm{Si}$ ratio of 0.6 for CNASH 0.6). Refer to ref. 24 for more details on the synthesis method and collection of the data. Synthetic gels are shown in pastel colors in the figure, while real gels are shown in dark colors.

This finding may have important implications for the use of synthetic C-(N)-A-S-H gels (and potentially synthetic C-S-H and $\mathrm{N}-\mathrm{A}-\mathrm{S}-(\mathrm{H})$ gels) as analogues for the actual gel found in AAS samples. Specifically, the distinct differences in nanocrystallinity implies differences in phase stability, where more metastable phases are found to have higher solubilities than their thermodynamically-stable phase counterparts. For example, it is well known that amorphous silica (metastable $\mathrm{SiO}_{2}$ phase) is much more soluble than crystalline quartz (most thermodynamically-stable phase of $\mathrm{SiO}_{2}$ at ambient temperature and pressure) [25]. Amorphous calcium carbonate is more soluble than crystalline calcite [26], and the same is true for amorphous calcium phosphate when compared with crystalline octacalcium phosphate [27]. It is important to note that the relative stabilities of phases can be augmented by surface effects, and specifically the surface energies associated with nanoparticles. For instance, it has been shown that amorphous alumina nanoparticles are more thermodynamically stable than their crystalline counterparts for a given particle size/surface area [28]. Nevertheless, additional research is needed to determine the thermodynamic properties of the real C-(N)-A-S-H gel in AAS to allow for direct comparison with the known properties of synthetic C-(N)-A-S-H gel [22].

Given the lower extent of nanocrystallinity of the real C-(N)A-S-H gel in AAS, together with the known amorphicity of NA-S- $(H)$ gel in AAMK, there is the opportunity to deliberately 
increase the nanoscale ordering of these gels with the aim to improve their thermodynamic stabilities and therefore increase their resistance to chemically-induced degradation. Careful control of this behavior would be necessary to ensure that an increase in crystallinity occurs during the initial formation of the paste whilst the material is still compliant, since later-age crystallization can lead to cracking and loss of mechanical strength ( $c f$., delayed ettringite formation in Portland cement paste). Enhancing the durability of concrete is an important aspect of sustainability in the concrete industry, since any repairs or need for concrete replacement leads to additional materials usage and associated $\mathrm{CO}_{2}$ emissions.

\section{The future of concrete and sustainability - learning from the energy transition}

As discussed in the preceding sections, certain technical challenges facing alternative cements such as short-term formation (i.e., setting), and optimal pore structure and permeability, can be investigated and manipulated via the use of key molecular- and nano-scale experimental (and theoretical) approaches. This research and associated knowledge are vital for predicting long-term performance of alternative cements, which will enhance uptake of these materials in the concrete industry. However, there are additional challenges facing the implementation of alternative cements in the concrete industry that are nontechnical in nature. Here, some of the most important nontechnical challenges are outlined and discussed in the context of the energy industry that recently underwent an important transition from purely coal to a range of diverse energy sources for electricity generation (including sustainable solar and wind generation). It is hoped that by using the energy transition as an example of where a large-scale industry has undergone substantial change in the face the climate crisis, readers will see that it is possible for a similar transition to occur in the concrete industry via the incorporation of more sustainable alternative cements.

\subsection{Energy transition overview}

The historical past of the energy sector, and specifically electricity generation, can provide insight on how an incumbent industry based primarily on a single technology can change in the face of competing technologies, climate change and pressure from the public and government. From Figure 8 it is clear that global energy usage from 1800 to 1920 was mainly provided by coal (excluding traditional biomass, i.e., wood), after which oil, followed by natural gas, emerged. Concentrating on the United States and electricity generation from 1950 to 2018, coal has played an enormous role until very recently (i.e., 2015) when natural gas became the dominant energy source for electricity generation (see Figure 9). Hence, since the inception of the incandescent light bulb by Thomas Edison in 1879 [29], coal had been a staple energy source for electricity generation.

The energy sector began to change in the early 1900s, with increasing amounts of oil, natural gas and hydroelectricity contributing to global energy usage (Figure 8). Natural gas became another fossil fuel option for electricity generation while oil fueled the transportation industry. Although there were significant concerns regarding oil and gas reserves and reliability of supply [33], access to unconventional oil and gas sources, such as natural gas in the United States via hydraulic fracking [34], has led to a significant surge in the use of natural gas for electricity generation, as clearly seen in Figure 9. Moreover, the discovery of nuclear fission in late 1930s led to the emergence of nuclear power plants for electricity generation in the 1970s (Figures 8 and 9) [35]. Hydroelectricity has been another staple energy source since the early 1900s, where damming of major rivers (such as the Colorado River by the Hoover Dam) and subsequent installation of water turbines led to the generation of renewable electricity. However, concerns regarding upstream and downstream ecosystems and the negative impact of damming have prevented proposed hydroelectric projects from being built in certain areas [36].

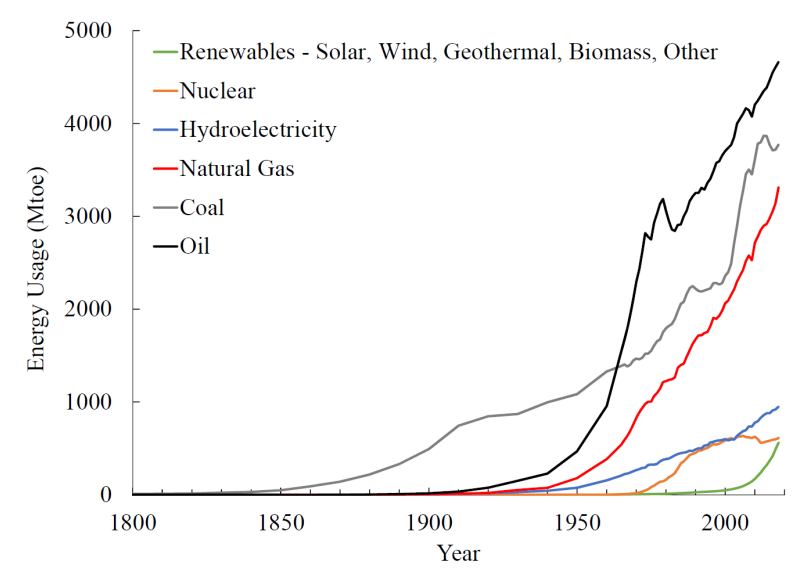

Figure 8. World energy usage by energy source, from 1800 to 2018, given in units of million tonnes of oil equivalent (Mtoe). Traditional biomass (e.g., wood) has not been included in this figure. Renewables include solar, wind, geothermal, biomass and waste. Data are from BP (Statistical Review of World Energy, 1965 - 2018) [30] and Our World in Data (Energy Production and Changing Energy Sources, 1800 - 1960) [31]. Data from Our World in Data were converted from units of terawatt-hours to Mtoe using the following conversion factors: 0.086 for coal, oil and natural gas, and 0.226 for hydroelectricity.

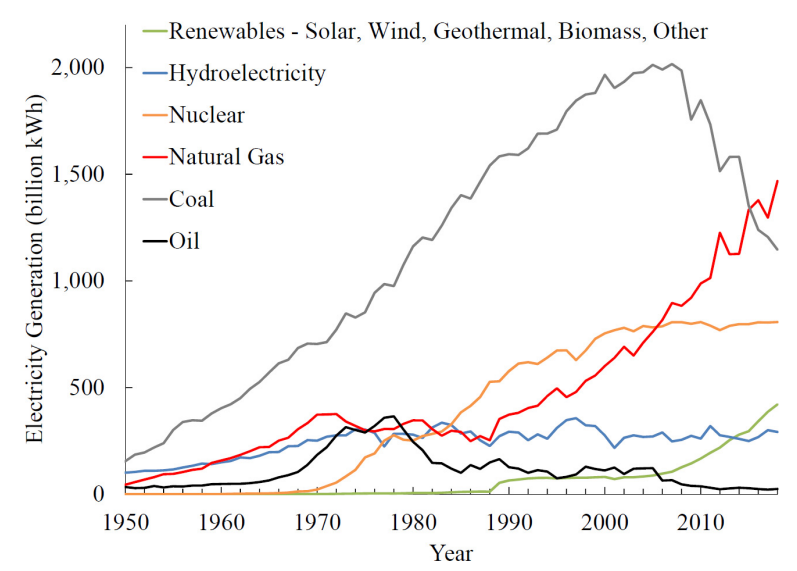

Figure 9. United States electricity generation by source, from 1950 to 2018 , given in units of billion kilowatt-hour. Renewables include solar, wind, geothermal, biomass and waste. Data are from U.S. Energy Information Administration [32]. 
In addition to hydroelectricity, there are a number of other renewable energy sources used for electricity generation including solar (i.e., photovoltaics and concentrated solar power), wind, geothermal, biomass, and waste. As shown in Figure 9 , use of these renewables for electricity generation has continually increased since 2005 , with natural gas also seen to increase during this time period. Hydroelectricity and nuclear have remained steady since 2005, while there has been a dramatic decrease in the use of coal. This shift from coal to natural gas and renewables in the United States is largely due to the lower cost of natural gas compared with coal together with the increase in the wind industry [37]. In 2018 wind-based electricity generation was responsible for $\sim 7 \%$ of total electricity generation in the United States while solar accounted for $\sim 2 \%$ [32]. Projections by the U.S. Energy Information Administration (2019) have renewables (including hydroelectricity) at $31 \%$ by 2050 with solar photovoltaics being responsible for $15 \%$ of total electricity generation [38].

\subsubsection{Photovoltaics}

The history of photovoltaics spans several centuries where in 1839 the photovoltaic effect was discovered [39]. The first photovoltaic device, where a current was generated by shining light (i.e., electromagnetic radiation) on a semiconductor, was demonstrated in 1954 using silicon, which was quickly followed by devices based on gallium arsenide and cadmium sulfide [39]. During the 1950s and 1960s photovoltaics were of significant interest to the space industry [39]. Nowadays photovoltaics are found in various industries, and, as discussed above, are rapidly emerging as a source for electricity generation [39]. Hence, although the technology was first invented in the 1950s, it has taken more than 50 years for photovoltaics to penetrate the energy sector. There are a number of reasons why photovoltaics took decades to become part of the energy sector. Firstly, their initial cost was prohibitive from an electricity generation perspective, specifically with a cost of approx. $\$ 1,500$ per Watt [39], compared with approx. \$1.1 per Watt for utility scale photovoltaics in 2018 [40]. Secondly, financial incentives and government policies in the United States have been instrumental in the growth of photovoltaics [41]. These, and other, factors have led to a growth of photovoltaics from $0 \%$ of United States electricity generation in 1983, to $1.6 \%$ in 2018 [32] and a projected 15\% in 2050 [38]. There are a number of reasons why intermittent renewables, such as solar and wind, are unlikely to solely supply all of our electricity needs in the future, the main reasons being the need for large scale energy storage and difficulties associated with smoothing out intermittencies of the grid [42], however, these challenges have not prevented industry and government from pursuing renewable (and more sustainable) sources of electricity. Hence, it is clear that the energy sector has transitioned from being heavily reliant on a single source of energy (i.e., coal) during the early $20^{\text {th }}$ century to now having a range of energy source options.

\subsection{A concrete transition in the future?}

As was the case of electricity generation relying on a single energy source during the early $20^{\text {th }}$ century, concrete was also dominated by a single technology, specifically Portland cement [43]. However, in contrast to the diversification that occurred in the energy sector regarding energy sources in the wake of climate change and sustainability, there has been minimal change in the concrete industry. In fact, Portland cement has been used as the main constituent in concrete for more than 150 years [43], with an annual cement production of 4.1 billion tonnes in 2018 (see Figure 10). The main approach used in industry to increase concrete performance and at the same time to improve sustainability has been to increase the use of supplementary cementitious materials (SCMs, e.g., blast furnace slag, fly ash, calcined clays, ground limestone) [2], yet these "sustainable" concretes are still based on Portland cement. Production of Portland cement and masonry cement in the United States in 2018 was 85.4 million tonnes and 2.4 million tonnes, respectively [44]. Alternatives concrete binders to Portland cement are never mentioned in global cement production data, implying that their quantities have yet to grow above baseline levels.

As documented in the literature, there are viable alternatives to Portland cement for use in concrete, some of which have been around for decades [47]. It is not the intent of this Letter to provide an extensive overview of these options, together with their advantages and disadvantages (akin to the advantages and disadvantages of different energy sources). However, it is important to point out a few of the numerous examples of where alternative concretes have been used in concrete structures going back decades, such as alkaliactivated concrete in the former Soviet Union [48] and calcium sulfoaluminate concrete in China [47]. Other sustainable alternatives to Portland cement include magnesium oxide cement (based on magnesium silicates) and carbonate cement derived from calcium silicates [49]. There are also a number of cement alternatives based on belite (a main clinker phase in Portland cement, second in quantity after alite) such as reactive belite-rich Portland cement and belite-ye'elimite-ferrite cement [49].

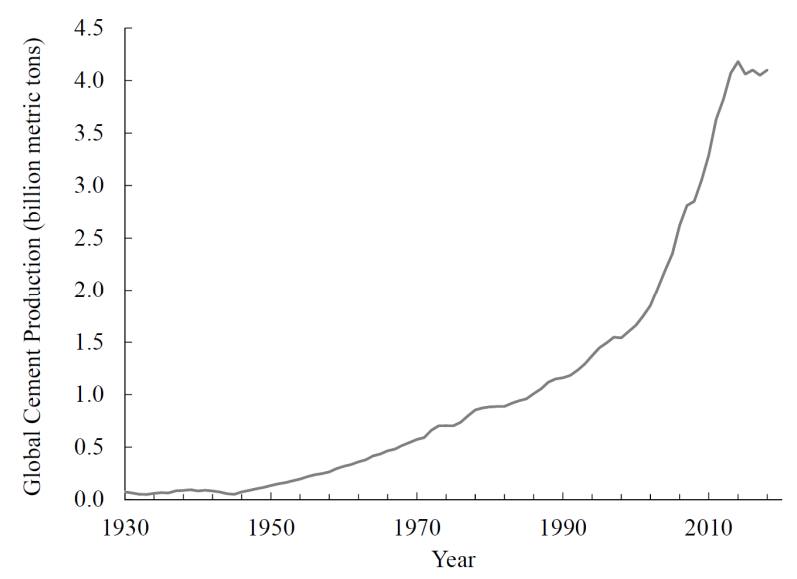

Figure 10. Global cement production from 1930 to 2018. In 2018 the United States produced 85.4 million tonnes of Portland cement and 2.4 million tonnes of masonry cement. Data are from U.S. Geological Survey [44-46]. 


\subsubsection{The scale issue}

Some have argued that the scale of the concrete issue restricts potential options [2], however, electricity generation also faces a scale issue which has been overcome by the industry adopting a range of alternatives (i.e., solar, wind, hydroelectricity) along with more traditional options (e.g., natural gas). Hence, although one concrete alternative may only have the ability to replace part of the demand for future construction, the synergistic use of a range of alternatives according to resource availability and intended application would lead to a sizable reduction in global $\mathrm{CO}_{2}$ emissions associated with the concrete industry. Furthermore, as coal usage in developed nations continues to decrease, supply of good quality fly ash will dwindle, leading to a shortage of this SCM for the concrete industry. This may not occur in certain developing nations such as India, since some projections on electricity generation show that coal may still play an important role moving forward. However, in general, there will be localized shortages of conventional SCMs around the world (i.e., fly ash and blast furnace slag), which will require the exploration and use of new SCMs (such as flash calcined kaolin). Implementation of alternative cements utilizing such abundantly available SCMs would lead to a significant reduction in $\mathrm{CO}_{2}$ emissions associated with the concrete industry.

\subsubsection{What about cost?}

Furthermore, the higher cost of alternative cements versus Portland cement is often used as a nonstarter for these alternative technologies [50]. If this approach was applied to photovoltaics when they were first commercialized in the 1950s and 1960s we would not have achieved the current milestones of their relatively low cost and increasing deployment around the world. It is rare for a new innovative technology to initially be cost competitive with a wellestablished industry. To help overcome the higher cost of photovoltaics compared with fossil fuel-based electricity sources local and state governments in the United States created financial incentives and policies for residential users of photovoltaics and electricity providers incorporating photovoltaics at the utility scale [51]. It is clear that if similar incentives and policies were implemented in the concrete industry these would significantly aid in the uptake of alternative cements from a cost perspective, and support early-age commercialization efforts. These incentives and policies would be best implemented in developed countries, where, although concrete usage would not rival the projected usage of developing countries, the usage of alternative cements would enable for the initial cost hurdles to be lowered (as was the case for photovoltaics), making them more affordable for subsequent use in developing countries.

\subsubsection{Standards and codes}

Another aspect of the construction industry seen as an enormous hurdle for innovative alternative cements is regulations [52]. The current concrete construction codes and standards in countries around the world are predominantly prescriptive focused, and explicitly mention the content of Portland cement required for a specified design strength [53].
Hence, by default no alternatives to Portland cement satisfy such codes and standards. In certain circumstances, such country-based standards have been replaced by organizationspecific performance-based standards, such as those that were created and implemented by the Roads Corporation of Victoria in Australia for alkali-activated concrete [54]. It has been acknowledged that switching to performance-based concrete standards would enhance the uptake of alternative cements in the construction industry [53], and recommendations for such performance-based standards are being developed by international organizations such as RILEM [54]. Nevertheless, the existence of performance-based standards may not correlate with rapid change in the concrete industry, since it is a very conservative industry and is adverse to risk, which likely includes the current avoidance of any existing performance-based standards. Therefore, external influences such as financial incentives may help overcome the perceived risk associated with use of performance-based standards for alternative cements, especially when used in low-risk non-structural elements such as sidewalks and roads.

\subsubsection{Public awareness and invested interest}

Lastly, it is clear that there is a disconnect between the use of concrete in society (and use construction materials in general) and the population's awareness of its environmental impact (particularly $\mathrm{CO}_{2}$ emissions). In contrast, nowadays, it is common for residents to be aware of their electricity usage together with the range of energy sources available for electricity generation. This has likely contributed to increased installation of residential photovoltaics, especially in developed countries, aiding the penetration of photovoltaics in the electricity sector. Another example of where society's awareness of existing technologies and environmental implications that has led to sustainable innovation is cars. Although electric cars have been around since the 1890s [55] it was not until recently that they became a popular alternative to gasoline cars. Electric cars are seen as a green alternative by society, albeit at the moment their "greenness" is highly dependent on their electric energy source for recharge since utility scale electricity is not fossil free at present. Hence, for both photovoltaics and electric cars, individuals in society are aware of the benefits of these technologies and their positive impact on the environment, which is likely attributed to these individuals having day-today interactions with electricity and car-based transportation. For cements, awareness of these alternative options is limited for design engineers and architects [52], let alone the billions of individuals that end up occupying concrete buildings or using concrete structures (e.g., bridges, footpaths, roads) on a daily basis. Therefore, increasing public awareness of the $\mathrm{CO}_{2}$ emissions associated with concrete, and highlighting the invested interest everyone has in how the world's infrastructure is built and maintained would enhance the global uptake of alternative cements.

\subsubsection{Moving forward}

It is clear from the energy industry and particularly electricity generation that government incentives have played a large role in the increase of renewables, as demonstrated by the 
United States electricity sector from 1950 to 2018. Similar incentives for the use of non-Portland cement-based concretes (i.e., alternative cements) would likely lead to an increase of these concretes in the construction industry. Furthermore, public support and advocacy of renewables has enhanced the uptake of these in the energy sector, even in the face of strong opposition from competing technologies and climate skeptics. Hence, public education and an associated increased awareness of industrial sources of anthropogenic $\mathrm{CO}_{2}$ emissions (e.g., cement, steel and plastics) together with sustainable alternatives would be a step forward to achieving effective public engagement. Pressure from the public can have a large impact on the operations of government and industry. However, the question remains how to increase and then sustain public support on a topic that is largely absent from most people's day-to-day life.

\section{Conclusions}

Given the $\mathrm{CO}_{2}$ emissions associated with Portland cement manufacturing and the existence of lower- $\mathrm{CO}_{2}$ alternative (i.e., non-Portland) cements with proven performance, it often comes as a surprise to the general public that these sustainable alternatives have yet to substantially penetrate the concrete industry. Here, the technical and non-technical hurdles preventing uptake of alternative cements in the concrete industry have been explored, where it was shown that key insight obtained from select molecular- and nanoscale experimental techniques can help overcome technical challenges relating to short-term performance and long-term durability. The development of new additives that control setting of AAMs (and other properties) is a technical hurdle that needs to be overcome. Moreover, it is necessary to understand the mechanisms by which these additives augment short-term behavior to ensure that these additives do not have unintended negative consequences on long-term performance. Here, it was shown that the setting of AASs can be carefully manipulated using nano-ZnO, and via use of PDF analysis and ICC, the mechanism by which this setting delay in AAS (and Portland cement paste) occurs was elucidated, together with the long-term behavior of $\mathrm{ZnO}$ within the paste. Another technical hurdle is the lack of long-term in-field performance of alternative cements. In conjunction with the development of appropriate accelerated testing protocols to determine performance under accelerated conditions, elucidation of fundamental paste characteristics will enable the relative performance of different types of AAMs (and alternative cements in general) to be predicted. In particular, the pore structure and associated permeability of a paste contributes to long-term performance of concrete, where a lower permeability paste with a percolated pore structure consisting of small pores (e.g., $<10 \mathrm{~nm}$ ) will have better resistance to chemically-induced degradation. Here, the pore structure of AAS and AAMK was investigated using nitrogen adsorption and mercury intrusion porosimetry, where it was shown that both techniques are needed to accurately capture the relative differences in pore structure for these AAMs. Moreover, it was shown that silicate-activated metakaolin consists of pores that are $\sim 10 \mathrm{~nm}$ in diameter at 150 days, in contrast with the larger pores ( 100 nm at 900 days) for hydroxide-activated metakaolin. Although the pore size of silicate-activated metakaolin at 150 days is seen to be close to that of Portland cement paste at $\sim 80$ days, absolute porosities will be different due to the higher water/metakaolin ratio of 0.9 compared with the lower water/cement ratio of 0.4 . Nevertheless, the recent emergence of flash calcined kaolin and the associated lower water demand of this material $(\leq 0.5)$ will have a favorable impact on the pore structure and permeability of AAMK in the future, making AAMs based on flash calcined kaolin of industrial interest.

The second part of this Letter focused on the non-technical hurdles preventing uptake of alternative cements in the concrete industry, where key hurdles were discussed in the context of recent sustainable alternatives that have successfully emerged in the energy sector. An overview of the energy transition was provided, where the historically dominant role of coal from 1800 to 1920 s has since been supplemented with a range of alternative energy sources including renewable electricity sources such as photovoltaics and wind generation in recent decades. This overview was followed by discussion of the perceived hurdles preventing use of alternative cements in the concrete industry including raw material availability, cost, regulations and public awareness, and how similar hurdles in the energy industry, and specifically electricity generation, were overcome. It is clear that financial incentives and public support had a large influence on the uptake of renewables for electricity generation, and these approaches would likely lead to a similar transition in the concrete industry. Hence, there is the potential for alternative (i.e., non-Portland) cements to play a crucial role in reducing the $\mathrm{CO}_{2}$ emissions associated with the concrete industry moving forward, however, it is critical that society becomes invested in reducing $\mathrm{CO}_{2}$ emissions from the industrial sector including those from the concrete industry.

\section{Acknowledgments}

This Letter was supported by funding from the National Science Foundation under Grant Nos. 1553607 and 1727346. CEW would like to thank Prof. Chris Greig and Dr. Eric Larson for discussions on the energy sector and data sources, and Prof. Jannie S. J. van Deventer for providing insightful feedback on a draft version of the Letter. CEW also acknowledges the work performed by Dr. Nishant Garg and Mr. Kengran Yang, specifically the ICC and PDF data (Dr. Garg) and pore structure data (Mr. Yang).

\section{References}

[1] OECD/International Energy Agency, World Business Council for Sustainable Development, Cement Sustainability Initiative, Technology Roadmap: Low-Carbon Transition in the Cement Industry, Paris, France, 2018.

[2] UN Environment, K.L. Scrivener, V.M. John, E.M. Gartner, Ecoefficient cements: Potential economically viable solutions for a low$\mathrm{CO}_{2}$ cement-based materials industry. Cem Concr Res (2018) 114: 226. https://doi.org/10.1016/i.cemconres.2018.03.015

[3] J.L. Provis, A. Palomo, C. Shi, Advances in understanding alkaliactivated materials. Cem Concr Res (2015) 78: 110-125. https://doi.org/10.1016/j.cemconres.2015.04.013

[4] Blyth, C.A. Eiben, G.W. Scherer, C.E. White, Impact of activator chemistry on permeability of alkali-activated slags. J Am Ceram Soc (2017) 100 (10): 4848-4859. https://doi.org/10.1111/jace.14996 
[5] M. Palacios, P.F.G. Banfill, F. Puertas, Rheology and setting of alkaliactivated slag pastes and mortars: Effect of organic admixture. $\mathrm{ACl}$ Mater J (2008) 105 (2): 140-148. https://doi.org/10.14359/19754

[6] Shi, B. Qu, J.L. Provis, Recent progress in low-carbon binders. Cem Concr Res (2019) 122: 227-250.

https://doi.org/10.1016/j.cemconres.2019.05.009

[7] G. Arliguie, J. Grandet, Influence de la composition d'un ciment portland sur son hydration en presence de zinc. Cem Concr Res (1990) 20 (4): 517-524. https://doi.org/10.1016/0008-8846(90)90096-G

[8] F.F. Ataie, M.C.G. Juenger, S.C. Taylor-Lange, K.A. Riding, Comparison of the retarding mechanisms of zinc oxide and sucrose on cement hydration and interactions with supplementary cementitious materials. Cem Concr Res (2015) 72: 128-136. https://doi.org/10.1016/j.cemconres.2015.02.023

[9] N. Garg, C.E. White, Mechanism of zinc oxide retardation in alkaliactivated materials: An in situ X-ray pair distribution function investigation. J Mater Chem A (2017) 5: 11794-11804. https://doi.org/10.1039/C7TA00412E

[10] Hou, C. Zhao, A.R. Paterson, S. Li, J.L. Jones, Local structures of perovskite dielectrics and ferroelectrics via pair distribution function analyses. J Euro Ceram Soc (2018) 38 (4): 971-987. https://doi.org/10.1016/j.jeurceramsoc.2017.12.003

[11] F. Ziegler, A.M. Scheidegger, C.A. Johnson, R. Dahn, E. Wieland, Sorption mechanisms of zinc to calcium silicate hydrate: X-ray absorption fine structure (XAFS) investigation. Environ Sci Tech (2001) 35 (7): 1550-1555. https://doi.org/10.1021/es001437+

[12] F.P. Glasser, J. Marchand, E. Samson, Durability of concrete Degradation phenomena involving detrimental chemical reactions. Cem Concr Res (2008) 38 (2): 226-246. https://doi.org/10.1016/j.cemconres.2007.09.015

[13] R.A. Cook, K.C. Hover, Mercury porosimetry of hardened cement pastes. Cem Concr Res (1999) 29 (6): 933-943. https://doi.org/10.1016/S0008-8846(99)00083-6

[14] Z. Zhang, G.W. Scherer, Evaluation of drying methods by nitrogen adsorption. Cem Concr Res (2019) 120: 13-26. https://doi.org/10.1016/j.cemconres.2019.02.016

[15] J. Zhang, G.W. Scherer, Comparison of methods for arresting hydration of cement. Cem Concr Res (2011) 41 (10): 1024-1036. https://doi.org/10.1016/j.cemconres.2011.06.003

[16] C.E. White, J.L. Provis, T. Proffen, J.S.J. van Deventer, Molecular mechanisms responsible for the structural changes occurring during geopolymerization: Multiscale simulation. AIChE J (2012) 58 (7): 2241-2253. https://doi.org/10.1002/aic.12743

[17] K. Yang, C.E. White, Modeling the formation of alkali aluminosilicate gels at the mesoscale using coarse-grained Monte Carlo. Langmuir (2016) 32 (44): 11580-11590. https://doi.org/10.1021/acs.langmuir.6b02592

[18] K. loannidou, K.J. Krakowiak, M. Bauchy, C.G. Hoover, E. Masoero, S. Yip, F.-J. Ulm, P. Levitz, R.J.-M. Pellenq, E. Del Gado, Mesoscale texture of cement hydrates. Proc Natl Acad Sci USA (2016) 113 (8): 2029-2034. https://doi.org/10.1073/pnas.1520487113

[19] J. Villadsen, Pore structure of cement based materials, Tech. Rep. 277, Building Materials Lab, Technical University of Denmark, 1992 (ISSN: 0908-3871).

[20] R. San Nicolas, M. Cyr, G. Escadeillas, Characteristics and applications of flash metakaolins. Appl Clay Sci (2013) 83-84: 253-262. https://doi.org/10.1016/j.clay.2013.08.036

[21] S.A. Greenberg, T.N. Chang, Investigation of the colloidal hydrated calcium silicates. II. Solubility relationships in the calcium oxide-silicawater system at $25^{\circ}$. J Phys Chem (1965) 69 (1): 182-188. https://doi.org/10.1021/j100885a027

[22] R.J. Myers, E. L'Hôpital, J.L. Provis, B. Lothenbach, Compositionsolubility-structure relationships in calcium (alkali) aluminosilicate hydrate (C-(N,K-)A-S-H). Dalton Trans (2015) 44 (30): 13530-13544. https://doi.org/10.1039/C5DT01124H

[23] L. Gomez-Zamorano, M. Balonis, B. Erdemli, N. Neithalath, G. Sant, C(N)-S-H and N-A-S-H gels: Compositions and solubility data at $25^{\circ} \mathrm{C}$ and $50^{\circ} \mathrm{C}$. J Am Ceram Soc (2017) 100 (6): 2700-2711. https://doi.org/10.1111/jace.14715

[24] N. Garg, V.O. Özçelik, J. Skibsted, C.E. White, Nanoscale ordering and depolymerization of calcium silicate hydrates in presence of alkalis. J Phys Chem C (2019) 123: 24873-24883. https://doi.org/10.1021/acs.jpcc.9b06412

[25] I. Gunnarsson, S. Arnórsson, Amorphous silica solubility and the thermodynamic properties of $\mathrm{H}_{4} \mathrm{SiO}^{\circ}{ }_{4}$ in the range of $0^{\circ}$ to $350^{\circ} \mathrm{C}$ at $P_{\text {sat. }}$ Geochim Cosmochim Acta (2000) 64 (13): 2295-2307. https://doi.org/10.1016/S0016-7037(99)00426-3
[26] L. Brečević, A.E. Nielsen, Solubility of amorphous calcium carbonate. J Cryst Growth (1989) 98 (3): 504-510. https://doi.org/10.1016/0022-0248(89)90168-1

[27] M.R. Christoffersen, J. Christoffersen, W. Kibalczyc, Apparent solubilities of two amorphous calcium phosphates and of octacalcium phosphate in the temperature range $30-42^{\circ} \mathrm{C}$. J Cryst Growth (1990) 106 (2): 349-354. https://doi.org/10.1016/0022-0248(90)90079-Z

[28] A.H. Tavakoli, P.S. Maram, S.J. Widgeon, J. Rufner, K. van Benthem, S. Ushakov, S. Sen, A. Navrotsky, Amorphous alumina nanoparticles: Structure, surface energy, and thermodynamic phase stability. J Phys Chem C (2013) 117 (33): 17123-17130. https://doi.org/10.1021/jp405820g

[29] T.A. Edison, Electric Lamp, United States Patent Office, Patent No. US223898A (1880).

[30] BP p.l.c., Statistical Review of World Energy - All Data, 1965-2018, 2019.

[31] H. Ritchie, M. Roser, Energy Production \& Changing Energy Sources, 2019.

[32] Monthly Energy Review July 2019: Table 7.2a Electricity Net Generation: Total (All Sectors), U.S. Energy Information Administration, 2019.

[33] J.D. Hamilton, Historical oil shocks in National Bureau of Economic Research Working Paper Series, Randall E. Parker and Robert Whaples (Eds.), New York, USA, Routledge Taylor and Francis Group, 2013, 239-265.

[34] D.J. Soeder, The successful development of gas and oil resources from shales in North America. J Petrol Sci Eng (2018) 163: 399-420. https://doi.org/10.1016/j.petrol.2017.12.084

[35] L.W. Davis, Prospects for nuclear power. J Econ Perspect (2012) 26 (1): 49-66. https://doi.org/10.1257/jep.26.1.49

[36] G. Law, The River Runs Free: Exploring \& Defending Tasmania's Wilderness, Camberwell, Victoria, Australia, Penguin Group Australia, 2008.

[37] H. Fell, D.T. Kaffine, The fall of coal: Joint impacts of fuel prices and renewables on generation and emissions. Am Econ J: Econ Polic (2018) 10 (2): 90-116. https://doi.org/10.1257/pol.20150321

[38] U.S. Energy Information Administration, Annual Energy Outlook 2019 - with projections to 2050, U.S. Department of Energy, Washington D.C., USA, 2019

[39] Fundamentals of Materials for Energy and Environmental Sustainability, D.S. Ginley, D. Cahen (Eds.), Cambridge, United Kingdom, Cambridge University Press, 2011.

[40] R. Fu, D. Felman, R. Margolis, U.S. Solar Photovoltaic System Cost Benchmark: Q1 2018, National Renewable Energy Laboratory, Golden, CO, USA, Report No. NREL/TP-6A20-72399, 2018. https://doi.org/10.2172/1484344

[41] O'Shaughnessy, State and Local Policy Impacts on the Residential Solar PV Installation Industry, National Renewable Energy Laboratory, Golden, CO, USA, Report No. NREL/TP-6A20-72149, 2019.

[42] W.M. Wang, J. Wang, D. Ton, Prospects for Renewable Energy: Meeting the Challenges of Integration with Storage in Smart Grid Integrating Renewable, Distributed and Efficient Energy, Fereidoon P. Sioshansi (Ed.), Waltham, MA, USA, Elsevier, 2012, 103-126. https://doi.org/10.1016/B978-0-12-386452-9.00005-X

[43] G.M. Idorn, Concrete Progress from Antiquity to Third Millenium, London, United Kingdom, Thomas Telford Publishing, 1997. https://doi.org/10.1680/cpftatttm.26315

[44] H.G. van Oss, Cement, in Mineral Commodity Summaries, U.S. Geological Survey, 2019.

[45] U.S. Geological Survey, Cement Statistics in Historical statistics for mineral and material commodities in the United States: U.S Geological Survey Data Series 140, Thomas D. Kelly and Grecia R. Matos (Eds.), 2015.

[46] H.G. van Oss, Cement, in Mineral Commodity Summaries, U.S. Geological Survey, 2018.

[47] M.C.G. Juenger, F. Winnefeld, J.L. Provis, J.H. Ideker, Advances in alternative cementitious binders. Cem Concr Res (2011) 41 (12): 1232-1243. https://doi.org/10.1016/j.cemconres.2010.11.012

[48] H. Xu, J.L. Provis, J.S.J. van Deventer, P.V. Krivenko, Characterization of aged slag concretes. ACI Mater J (2008) 105 (2): 131-139. https://doi.org/10.14359/19753

[49] Gartner, T. Sui, Alternative cement clinkers. Cem Concr Res (2018) 114: 27-39. https://doi.org/10.1016/i.cemconres.2017.02.002

[50] K.L. Scrivener, R.J. Kirkpatrick, Innovation in use and research on cementitious material. Cem Concr Res (2008) 38 (2): 128-136. https://doi.org/10.1016/j.cemconres.2007.09.025

[51] Barbose, N.R. Darghouth, S. Weaver, D. Feldman, R. Margolis, R. Wiser, Tracking US photovoltaic system prices 1998-2012: A rapidly 
changing market. Prog Photovoltaics (2015) 23 (6): 692-704. https://doi.org/10.1002/pip.2482

[52] J. Giesekam, J.R. Barrett, P. Taylor, Construction sector views on low carbon building materials. Build Res Inf (2016) 44 (4): 423-444. https://doi.org/10.1080/09613218.2016.1086872

[53] R.D. Hooton, Bridging the gap between research and standards. Cem Concr Res (2008) 38 (2): 247-258. https://doi.org/10.1016/j.cemconres.2007.09.012

[54] J.S.J. van Deventer, D.G. Brice, S.A. Bernal, J.L. Provis, Development, Standardization, and Applications of Alkali-activated Concretes in Geopolymer Binder Systems, L. Struble and J. Hicks (Eds.), West Conshohocken, PA, USA, ASTM International, 2013, 196-212. https://doi.org/10.1520/STP156620120083

[55] D.P. Billington, Ford, Sloan, and the Automobile in Power, Speed, and Form: Engineers and the Making of the Twentieth Century, Princeton University Press, 2006, 79-102.

https://doi.org/10.1515/9781400849123-009 